\title{
PARAPLEROMATIC LUCUBRATIONS
}

\author{
INEKE SLUITER \\ Vrije Universiteit Amsterdam \\ Institute for Advanced Study, Princeton
}

Not unlike their modern counterparts, ancient linguists like neat and all-encompassing classifications. Their main theoretical framework, the system of the parts of speech, is designed to accommodate every instance of each and every word in the process called $\mu \varepsilon p t \sigma \mu{ }^{\zeta}$ ('parsing'). The partes orationis were defined by a combination of formal and semantic considerations, to which essential syntactic information could be added (as in 'adverbs tend to go with verbs'). The latter type of information was considered part of the general semantics of a word class and tended to be confined to observations on the physical combinations of words and their equally physical positions vis-à-vis each other. The main partes were subdivided into numerous subcategories, again mostly on the strength of semantic criteria. Dionysius Thrax, for instance, enumerates 26 different types of adverbs, all of which are purely defined by

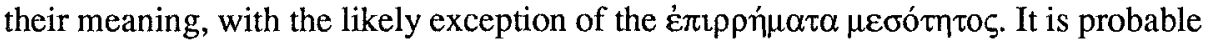
that the primary trait this latter group has in common is a morphological one, namely their ending in $-\omega \zeta$. Similarly, he distinguishes eight (or nine) types of 'conjunctions', 1 all of which are defined by their function or their semantic loadoften the two are hard to distinguish (D. Th. 87.1ff.).

As with any system descriptive of language, the actual empirical material turned out to be recalcitrant, and to resist complete pigeonholing in terms of the partes that were distinguished. This appears from the elaborate discussions Apollonius Dyscolus devotes to the classification of problematic words, and which he habitually inserts between his discussion of the definition, syntax and semantics of each part of speech and the more detailed discussion of the morphological characteristics of specimina belonging in each part. Such discussions are extant e.g. in his De pronominibus (pron. 26.23 - 35.5) and De adverbiis (adv. 126.24 - 145.25), while a similar section from De coniunctionibus (coni.) got lost in the lacuna after coni. $214.26{ }^{2}$

However, the framework of the partes orationis itself offered some room to accommodate borderline cases, in that it contained several categories which were capable of absorbing precisely those words whose meristic characteristics were less clear-cut. The adverb is probably the best example. Any word which is used in a way that sets it off from the part of speech to which it would usually be taken to belong,

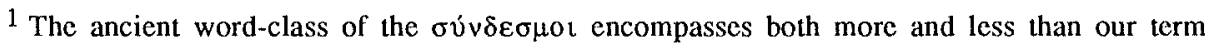
'conjunctions'. I will use the word in inverted commas to draw attention to this fact.

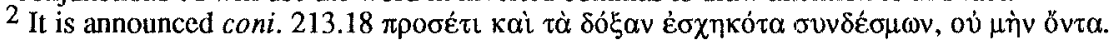


becomes an adverb ${ }^{3}$ For instance, any declindble word which is used in an adverbial way thereby turns into an adverb itself ( $a d v 1201 \mathrm{ff}$ ) As we will see, the subclassification of the 'conjunctions' ( $\sigma v^{v} \delta \varepsilon \sigma \mu o r$ ) contains a potentıal receptacle for residual

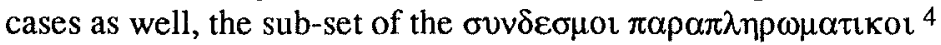

In the following I will argue that the theoretical distinction of this group of particles in antiquity develops out of the debate on whether or not 'conjunctions' have meaning, and an interest in the rhetorical and stylistic effects of redundancy Later grammatical theory adopted the group with traces of its background in stylistic theory shining through, and exploited its potential to function as a port-manteau category in its word-class system

'Conjunctiors' ( $\sigma v v \delta \varepsilon \sigma \mu \mathrm{s})$ were a recognized linguistic category from Aristotle onwards (Poet 1456b39ff), but the subcategory of the $\pi \alpha \rho \alpha \pi \lambda \eta \rho \omega \mu \alpha \tau \kappa o$ was a later addition to linguistic theory Summanzing the relatively late locus classicus on the topic (Ap Dysc coni 24722 - 25826 ), the group can provisionally be defined as consisting of particles with a wide range of meanings, but sharing the characteristic that they are also (and even predominantly) used without any distınguishable semantic or syntactic impact or purpose, to 'fill out' or embellish metre and style Their name derives from this common element, because it is more practicable than multuplying the number of types in an inordinate way by naming every one of these 'conjunctions' after their very diverse meanings

It is likely that distinction of this category wds facilitated by more general discussions about the question whether or not syndesmol ds a group had meaning Aristotle had categoncally denied this, ${ }^{5}$ and traces of the debate can be found in Posidonius (apud Apollonius Dyscolus) ${ }^{6}$ Only after a consensus had been established that the 'conjunctions' in general did have medning, did the need arise for a separate subcategory which could deal with those instances that to all intents and purposes did not Yet, from the beginning stylistic implications dre more important than semanticosyntactic ones [Ar] Probl XIX 20 (919a), often adduced in discussions of para pleromatic particles, is usually interpreted as an early recognition of the non-necessary character of 'some' syndesmol, and this is taken to refer to their semanticosyntactic qualities However, a closer look at the context reveals that this is not its

\footnotetext{
3 The adverb was called pandectes for that very reason, e g Charısius $25229 \mathrm{ff}$ B cum adverbium Stotcl pandecten vocent nam omnia in se captl quast collata per saturam concessa sibt rerum varia potestate, Clemens Ars grammatica (ed Tolkıchn) $8817 \mathrm{ff}$ IIoc quoque intuendum quod haec pars id est adverbium duo nomina habet apud Graecos id est 'eptrrhema' quod interpretatur 'adverbtum' et 'pandecten' quod interpretatur omne dictum [this is wrong, of course], quia omnts pars oratlonis cum desintt esse quod est adverbium fit

${ }^{4}$ Hellwig (1974 149f) considers this category an ad hoc solution like the vague modern class of 'particles' Schenkeveld (1988) demonstrates that 'particle' 1s not an ancient concept

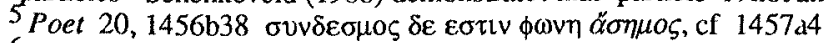

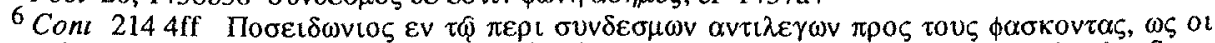

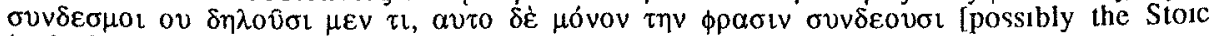
'orthodoxy', cf D L VII 58] This is Posidonius the Stotc (135 50 BC), not the grammarian, sec Baratun (1989 $25 \mathrm{n}$ 2), Atherton (1993 305, $306 \mathrm{n} 77$ ), for the passage, sec Bell (1982), Sluter (1990 117 n 293)
} 
primary intention, nor does it seem to envisage only those particles which were later styled parapleromatic.

In this 'Problem', [Aristotle] is dealing with music and in particular with the nature of the tone called mese. If this tone is out of tune, the whole melody will sound unpleasant, whereas other tones would just sound unpleasant themselves under the circumstances, but would not affect the whole. The author explains this as follows:

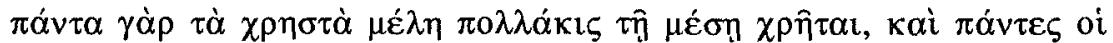

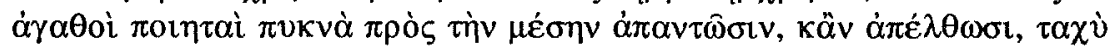

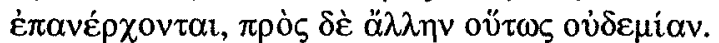

'For all the best tunes make frequent use of the mese, and all good musicians search it out frequently, and quickly revert to it, even if they leave it, but not to any other note to the same extent' (tr. Hett, adapted).

Then follows a linguistic analogy:

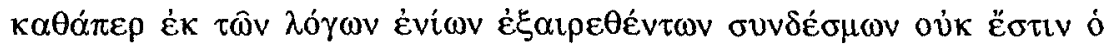

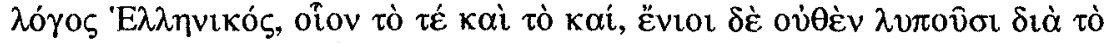

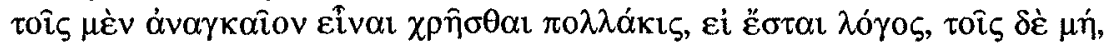

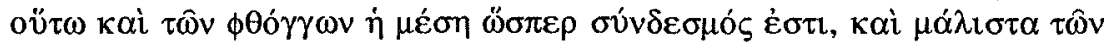

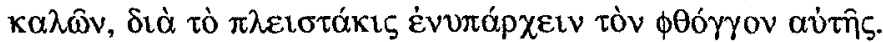

"Just as when from discourse certain "conjunctions" are removed, the language is not (good) Greek, e.g. te and kai, while others can be removed without harm (for it is necessary to use some of them frequently for there to be discourse at all, but for others that is not the case); in the same way the mese is as it were the "conjunction" of musical sounds, especially of good music, because its sound must have a very frequent place in it.'

The author compares the mese to 'conjunctions' that need to be employed frequently, and are opposed to ones that can be left out without harm. The distinction is not, therefore, between $\dot{\alpha} v \alpha \gamma \kappa \alpha \hat{\imath} \mathrm{o}$ and $\mu \grave{\eta} \dot{\alpha} v \alpha \gamma \kappa \alpha \hat{\imath} o \mathrm{r}$ as such, but between 'conjunctions' that need to be employed frequently and those that do not. This is

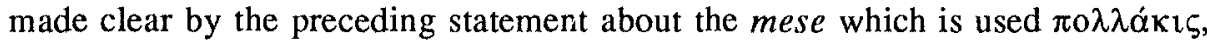
searched out $\pi v \kappa v \alpha$ and reverted to $\tau \kappa \chi v$. The emphasis on style is confirmed by the repeated reference to the quality of the music ( $\pi \alpha \dot{v} \tau \alpha \tau \dot{\alpha} \chi \rho \eta \sigma \tau \dot{\alpha} \mu \varepsilon \dot{\lambda} \eta)$ and the composers ( $\pi \alpha \dot{v} \tau \varepsilon \zeta$ oi $\dot{\alpha} \gamma \alpha \theta$ oi $\pi 0 \imath \eta \tau \alpha i$ ). In the linguistic analogy, the author seems to be

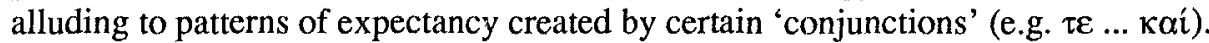
This would mean that not only parapleromatic particles, but also e.g. 'conjunctions' like $\gamma$ ó $\rho$ belong in the group that can be removed without making the text incoherent.

When read this way, the text fits in perfectly with a whole series of early rhetorical treatises imparting stylistic advice on the audience-friendly use of syndesmoi. ${ }^{7}$

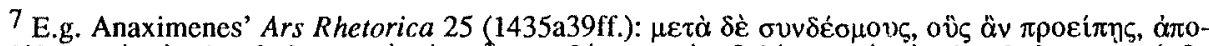

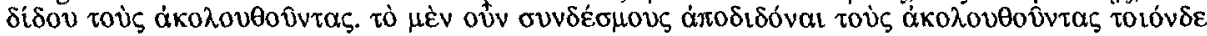


Their correct use will lead to clanty and Hellensmos In Aristotle's Rhetoric, the first

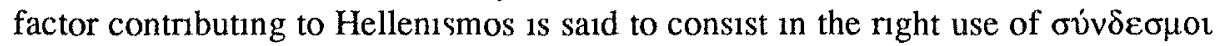
(Rhet III 5, 1407a19ff)

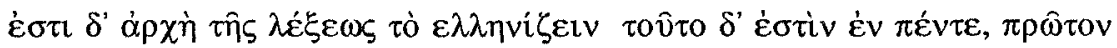

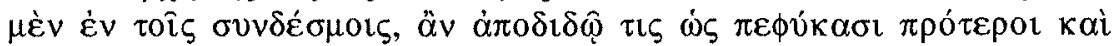

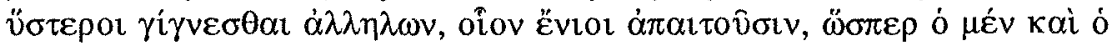

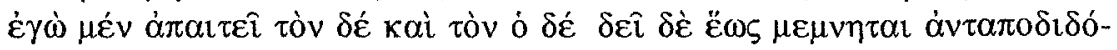

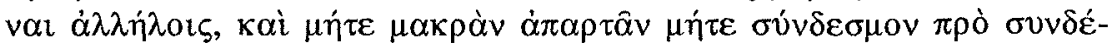

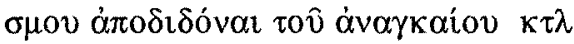

'The beginning of good style is Hellenısmos, pure Greek This consists in five elements, first in the use of "conjunctions", if one makes them correspond in their natural order of priority and posterionty, the way some of them require E g men and ego men require de and ho de They should be made to correspond to one another as long as they are still fresh in memory, and should not be made to connect at a long distance, nor should one make a different "conjunction" correspond instead of the necessary one "

The desirable quick resolution of the expectancy created by a syndesmos corresponds to the way good composers quickly revert to the mese in the Problemata

The concept of the parapleromatic syndesmoi thus seems absent from the pseudo-Aristotelian Problemata, although the stylistic qualities of syndesmo in general were recognized and would eventually be helpful in their distinction (In fact, in contrast to the position taken in the Problemata, they would become the syndesmot with a virtually exclusively stylistic impact par excellence) Neither can the $\pi \alpha \rho \alpha-$ $\pi \lambda \eta \rho \omega \mu \alpha \tau \iota \kappa o l$ have commanded the particular interest of the furst Storc language theorists Their theory of the 'conjunction' was limited to its logical uses for the construction of complex propositions, which are precisely defined by the type of 'conjunction' connecting their parts (D L VII 71ff) By their very nature, the parapleromatic ones would escape notice in that context However, there are two contexts

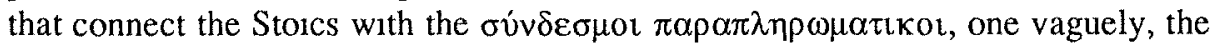
other explicitly The first is in D L VII $67^{8}$ Here, in the Stoic version of speech-act theory, a distinction is made between axiomata, the bearers of truth and falsity, and

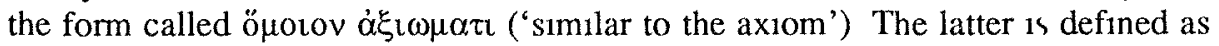
follows

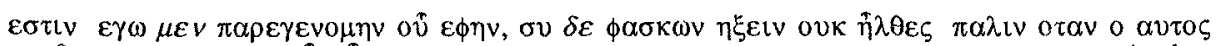

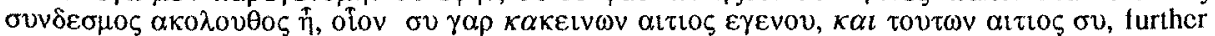
Isocrates apud Syrranus in Hermog I $286 \mathrm{R}$, Max Planudes, V $469 \mathrm{Wal} /$ and Jodnnes Siceliota, VI

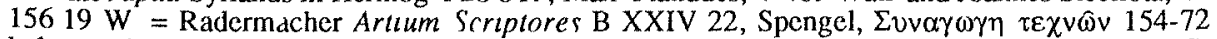

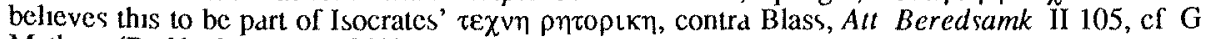
Mathıeu (Budé edition IV, 233t)

${ }^{8}$ Professor Schenkeveld pointed out the relevance of this text to me 


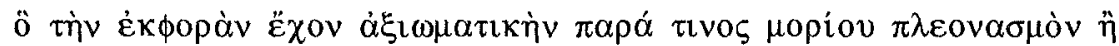

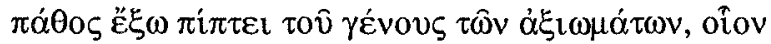

$\kappa \alpha \lambda o ́ \varsigma \gamma^{\prime}$ ò П $\alpha \rho \theta \varepsilon v \omega ́ v$

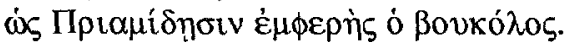

'that which having the form of an axiom falls outside the class of axioms because it exceeds it by an extra word or by emotion, e.g.

Beautiful indeed the Parthenon!

How does the cowherd resemble Priam's sons!'9

Note that neither the term $\sigma \dot{v} \delta \delta \varepsilon \sigma \mu \rho \zeta$ nor that of $\pi \alpha \rho \alpha \pi \lambda \eta \rho \omega \mu \alpha \tau$ Kó $\zeta$ is used in this context. $\Gamma \varepsilon$ certainly qualifies as a parapleromatic 'conjunction' in later theory, but $\dot{\omega} \xi$ is an adverb. Note also that the examples are both poetic. I will return to this passage later.

The second instance stems from a period in which a more general overview of grammar was extrapolated from Stoic work on logic, and attempts were being made to provide language descriptions with a claim to exhaustiveness. In that context, we know that the Stoic Chaeremon (a teacher of Nero's), who wrote on 'conjunctions', devoted some attention to the question of the classification of the parapleromatic 'conjunctions' in view of their alleged lack of meaning. ${ }^{10}$ It would seem that by this period 'conjunctions' as such were agreed to have meaning - the subcategories in Dionysius Thrax are after all semantic or functional in nature. It was the subcategory of the parapleromatic 'conjunctions' that had become the focus for discussion of the problematic notion of absence of meaning. This aspect was then combined with an element inherited from earlier Peripatetic observations on the class of 'conjunctions' as a whole, namely an interest in the rhetorical and stylistic function of these syndesmoi.

The earliest attestations of the use of $\pi \alpha \rho \alpha \pi \lambda \eta \rho \omega \mu \alpha \tau$. BC. We know that both Tyrannio (early 1st cent. BC) and Trypho (contemporary of Augustus) discussed this class. P. Yale 1.25 (1st cent. AD) lists it as one of the classes of the $\sigma v 0 \delta \varepsilon \sigma \mu o t$. The discussions by Tyrannio and Trypho suggest that Dionysius Thrax indeed knew this sub-category, although the part of his Techne that contains its description amply postdates him. His description does not ascribe any meaning to this category, but neither does it define them by the absence of meaning.

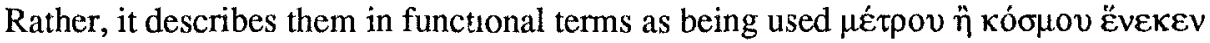
'for the sake of metre or ornament' (D. Th. 96.3f.). Many ancient interpreters connect this view on the $\pi \alpha \rho \alpha \pi \lambda \eta \omega \mu \alpha \tau$ coi with the clause in Dionysius' over-all definition of $\sigma \dot{v} \delta \delta \varepsilon \sigma \mu \circ$ (D. Th. 86.3f.):

${ }^{9}$ Cf. Schenkeveld (1984: 303, 307, 315).

${ }^{10}$ Chaeremon: Ap. Dysc. coni. 248.1 . 


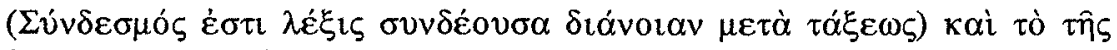

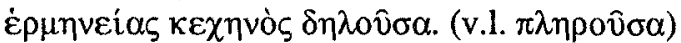

"(A "conjunction" is a word that connects the thought while expressing order,) and it indicates (or: fills) the hiatus of the language'

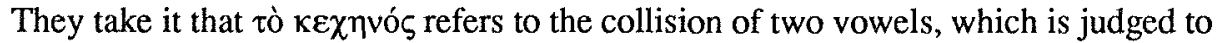
be a stylistically unpleasant effect, and that the $\pi \alpha \rho \alpha \pi \lambda \eta \rho \omega \mu \alpha \tau \iota \kappa o i$ are the subgroup that performs this syndesmic function par excellence.

The alternative and more sophisticated (but also more far-fetched) ancient interpretation is that the last clause of the definition allows the inclusion of the $\delta 1 \alpha \zeta \varepsilon v-$

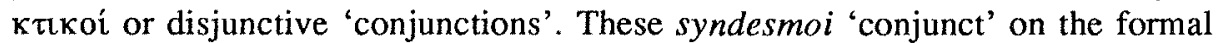
level, but their meaning is to exclude, to separate off. It can however be described as 'filling/indicating the gaps of discourse', in the sense that they make the connection of thought explicit. ${ }^{11}$ Baratin (1989: 38) generalizes the applicability of the clause

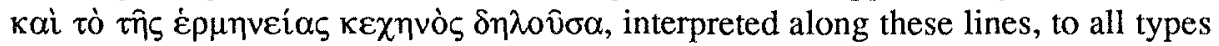
of conjunctions. ${ }^{12}$ I find his reading convincing as an attempt at a charitable and maxımizing interpretation, but will concentrate in what follows on the ancient views, which predominantly take the more obvious route and understand the clause as referring to hiatus.

The use of parapleromatic particles smoothens and remedies the harshness created by hatus, and renders the language more euphonic. Of the technical grammarians, notably Trypho is of this opinion, and he famously compared parapleromatic 'conjunctions' with 'padding ( $\sigma \tau 0 \iota \beta \eta)$ to prevent jarring and breaking of amphoras'.13 When Apollonius Dyscolus is describing this euphonic use of 'conjunctions', he compares it to that of the ephelcustic - $v-$. Interestingly, the use of such $\mathrm{a}-\mathrm{v}$ - is referred to in pron. 50.11 as:

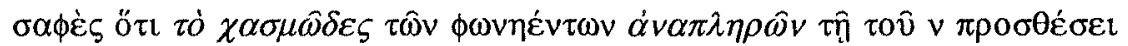
(sc. Homerus)

'clearly fillng out the hiatus of the vowels by the addition of the $n u$ ',

11 See Uhlig ad D Th. 86.3-4, and e g. Sch. D Th. 103.9-12; 436.23

12 He seems unaware of the anticipation of his interpretation by the Scholiast on D. Th. $436.30 \mathrm{ff}$

13 Ap. Dysc. conı 252.31; 253.2; 253.9f In 25232 Apollonius is clearly alluding to Trypho's description of these 'conjunctions' as 'padding', showing that he derives his own views on their euphonic use from him (although he rejects the view that a whole part of speech should owe its

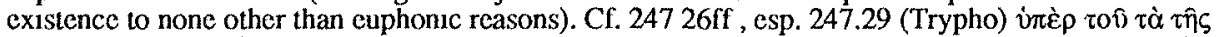
$\phi \rho \alpha \alpha \varepsilon \omega \varsigma \mu \eta \dot{~} \tau \rho \alpha \chi v ́ v \varepsilon \sigma \theta \alpha$ t. Apollonius claums that Trypho added a clause to his definition of the $\sigma u ́ v \delta \varepsilon \sigma \mu o \mathrm{l}$ as a group in order to be able to include these meaningless particles, which do not

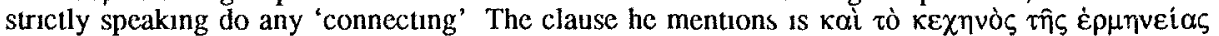

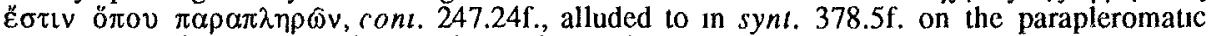

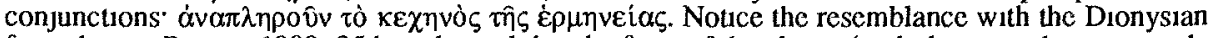
formulation. Baratın 1989: 35 has claimed that the form of the clause (with the masculine participle $\pi \alpha \rho \alpha \pi \lambda \eta \rho \omega \mathrm{v})$ makes it unlikely that it actually belonged in the definition of the whole pars orationis, since in that case one would have expected either a feminine form to correspond with

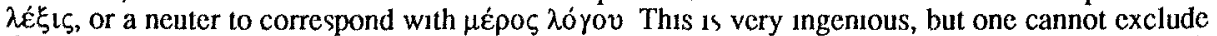
the possibility that Apollonius' quotation has undergone 'grammaticalization of the lemma', which would typically yıeld the nominative masculine (c. Tosi 1988). 
thus illustrating how naturally this interpretation fits in with normal linguistic usage. Indeed, there can be no doubt that the natural reading of tò $\chi \alpha \sigma \mu \omega \hat{\omega} \delta \varepsilon \zeta$ and iò $\kappa \varepsilon \chi \eta$ vó $\zeta$ is that it refers to hiatus between vowels. ${ }^{14}$

The avoidance of hiatus takes us straight back to stylistics. This fits right in with the fact that some of our earliest testimonies for the $\pi \alpha \rho \alpha \pi \lambda \eta \rho \omega \mu \alpha \tau$ เ o i (as opposed, this time, to the group of syndesmoi as a whole) also take the form of stylistic recommendations. Protesting against their idle use, pseudo-Demetrius prescribes them only if one wants to produce an effect of grandeur (Eloc. 55ff.):

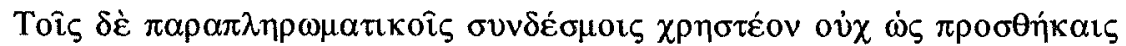

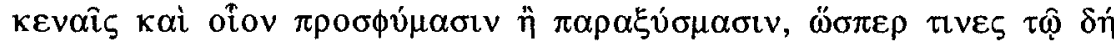

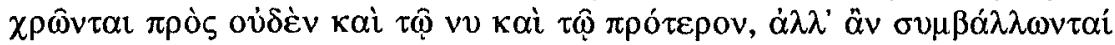
$\tau \imath \tau \hat{\omega} \mu \varepsilon \gamma \varepsilon \dot{\theta \varepsilon \imath} \tau o \hat{v} \lambda o ́ \gamma o v$...

"One should use the parapleromatic "conjunctions" not as empty additions, and as it were as abnormal growths or superfluous polishing, the way dê and $n u$ and proteron are sometimes used without a purpose, but only if they contribute something to the grandeur of the language'

One way of doing this is to use $\delta \dot{\eta}$ to amplify the beginning of a statement-this emphasizes the divide between two statements and makes for a dignified impression (Eloc. 56). Another function of the particle $\delta \dot{\eta}$ is to invest discourse with pathos (Eloc. 57). Pseudo-Demetrius refers to Praxiphanes, a student of Theophrastus', who

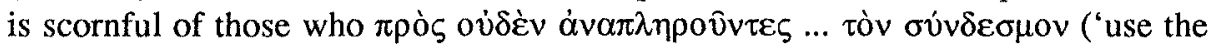
"conjunction" as an idle filler') (Eloc. 58). This is another indication of the stylistic interest taken in 'conjunctions' in general in the Peripatos, but although the context is suggestive, it cannot be proven that Praxiphanes was thinking of the parapleromatic 'conjunctions', identified as a separate group. Praxiphanes is not pseudo-Demetrius. He compares the idle use of words like $v v$, but also like $\pi \rho$ ó $\tau \varepsilon \rho o v$, with actors' interpolations of interjections like $\phi \varepsilon v \hat{v}$ and aï ciı used extra metrum. (In fact, such a bad use of these syndesmo $i$ would probably make them fall outside the scope of Dionysius Thrax' definition, since they do not fill out the metre at all, but ruin it in a way.) In general, the whole context - as far as it can be made out from the poor transmission-emphasizes nut the mere fact of $\dot{\alpha} \alpha \alpha \pi \lambda \eta \rho 0 \hat{v}$, or of being a $\pi \rho \circ \sigma \theta \dot{\eta} \kappa \eta$, but the

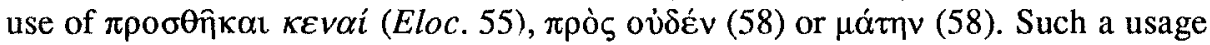
violates the rhetorical requirement of $\tau$ ò $\pi \rho \dot{\varepsilon} \pi \circ \mathrm{v}$, and this is confirmed by the use of

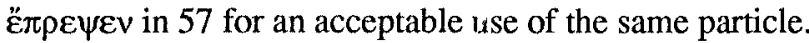

The text in pseudo-Demetrius rewards further analysis. The terms $\pi \rho$ ó $\sigma \phi v \mu \alpha$ and $\pi \alpha \rho \alpha \dot{\xi} v \sigma \mu \alpha$ have no parallels in a stylistic context. Both are used metaphorically, much like $\sigma \tau o \iota \beta \eta$ 'padding' was in Trypho, a $\pi \rho$ ó $\phi \nu \mu \alpha$ being any kind of growth

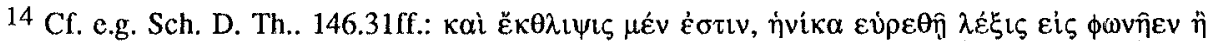

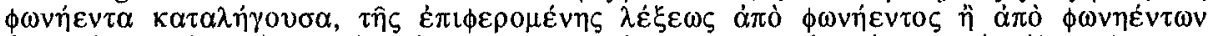

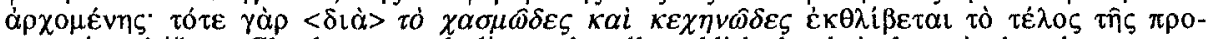

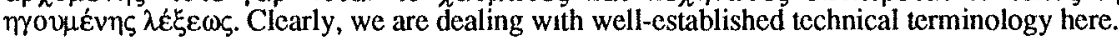


that is 'in addition to (the natural constitution?)' ( $\left.\pi \rho{ }^{\prime}\right)$ ), ${ }^{15}$ while $\pi \alpha \rho \alpha \dot{\xi} \xi \sigma \sigma \mu \alpha$ may either mean 'extra scratches, extra letters', ${ }^{16}$ or maybe 'a result of excessive polishing'. ${ }^{17} \Pi \alpha \rho \alpha \dot{\alpha}$ - in $\pi \alpha \rho \alpha{ }^{\prime} \xi v \sigma \mu \alpha$ points at the undue, excessive or redundant nature of

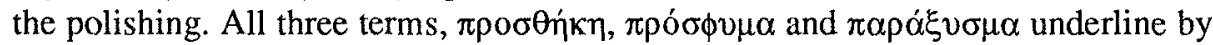
their pseudo-etymologizing the essential redundancy of the $\pi \alpha \rho \alpha-\pi \lambda \eta \rho \omega \mu \alpha \tau t \kappa o ́ s$. Whereas compounds of $\pi \lambda \eta p o ́ \omega$ are routinely used to denote syntactic or semantic completion, i.e. the necessary completion of a semantic and syntactic structure, a $\pi \alpha \rho \alpha \pi \lambda \eta \rho \omega \mu \alpha \tau$ Kó $\varsigma$ does its 'filling out' over and above what is strictly speaking required or necessary in those respects.

Unlike $\pi \rho o ́ \sigma \phi v \mu \alpha$ and $\pi \alpha \rho \alpha \dot{\xi} \xi v \sigma \mu \alpha, \pi \rho \circ \sigma \theta \eta \dot{k} \eta$ resonates widely in the field of stylistics. Dionysius of Halicarnassus describes a certain $\kappa \hat{\omega} \lambda \lambda_{0} v$ in Plato as an

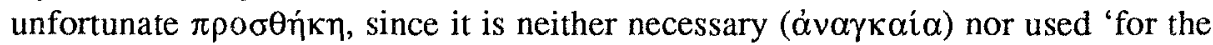
sake of beauty, or another form of additional ornamentation. ${ }^{18}$ These possibilities

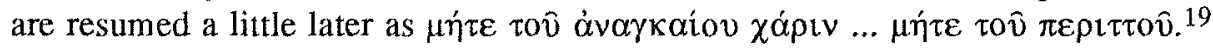

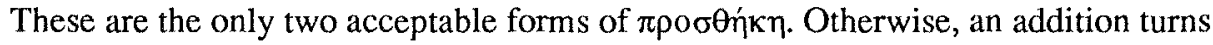
into $\dot{\alpha} \kappa \alpha \iota p i \alpha$, 'bad timing, bad taste'. Clearly, the word 'redundant' ( $\pi \varepsilon \rho \iota \tau \tau$ s) by itself does not exclude a contribution to beautification, as did the pseudo-Demetrian

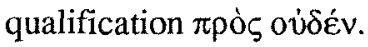

Further, $\pi \rho \circ \sigma \theta \hat{\eta} \kappa \alpha l$ are a stock-issue in the context of the theory of the three

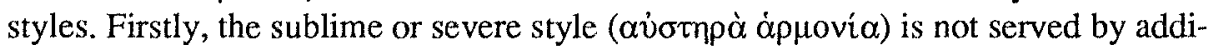
tions that smoothen stylistic ruggedness, since that is the very core characteristic of this style. Its aim is not to be periodical, so it avoids $\pi \rho 0 \sigma \theta \hat{n} \kappa \alpha \mathrm{t}$ that do not contribute to the sense. ${ }^{20}$ Interestingly, the same concept is also expressed using $\pi \alpha \rho \alpha$ $\pi \lambda \eta \dot{p} \omega \mu \alpha$ (D. H. Dem. 39.212.20ff.):

(the severe style uses asymmetrical periods), $\mu \eta \delta \varepsilon$ $\gamma \varepsilon \pi \alpha \rho \alpha \pi \lambda \eta \omega \dot{\varepsilon} \mu \alpha \sigma \tau \hat{\omega} v$

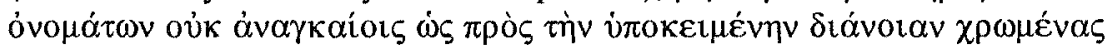
'without using filler words that are not necessary for the underlying meaning'

\footnotetext{
15 One is strongly reminded of Sch. D. Th. 356.15ff., explaining why the Stoics had not recognized

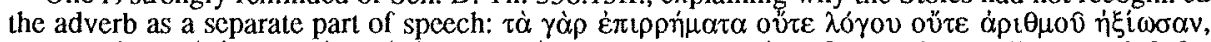

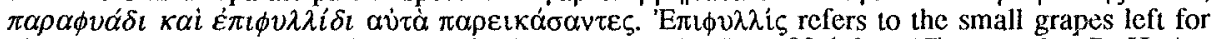
gleaners; it was used metaphorically for bad pocts in Ar. Ran. 92 (cf. n. 17), quoted in D. H. Ars Rhet. X 18 to describe epilogues in a deprecating way after first having called them a sort of dessert after the main meal. The compound with émi-may again have been found attractive for a description

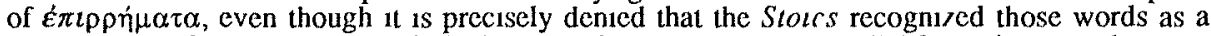

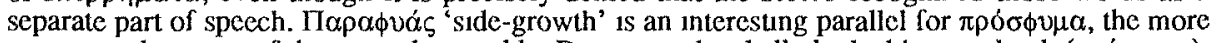

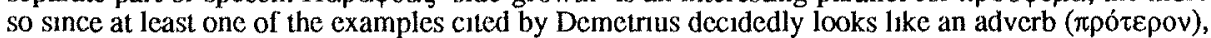
see below.

$16 \Xi v \sigma \mu \alpha \tau \alpha=\gamma \rho \alpha \dot{\mu} \mu \mu \alpha \tau \alpha$, Hsch.

17 Rather than the 'filıngs' or 'shavings'. Cf, for the metaphor C1c. Brut. 93; Hor. Ars 291; Ov. Tr. 1.7.30 (ultıma lıma); Qunt. 10.4.4. An interesting verbal parallel is Ar. Ran. 881 (cf. n 15)

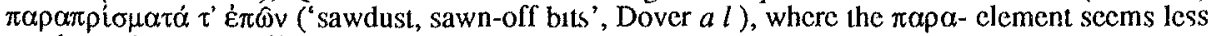

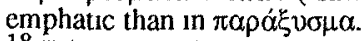

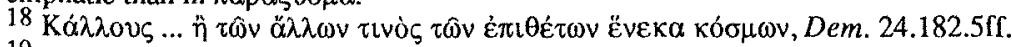

19 D. H. Dem. 24.182.20f.

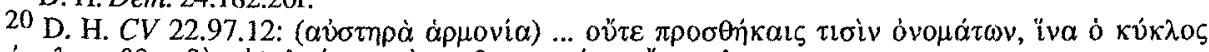

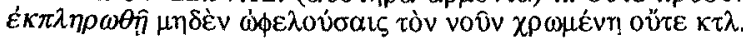




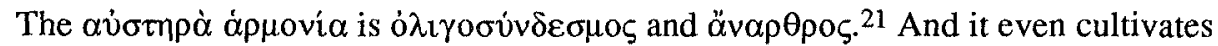

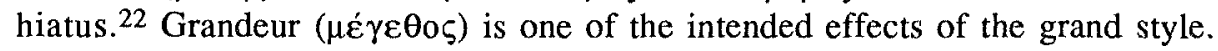
Longinus (De subl. 21.2) points out that 'syndesmoi and other $\pi \rho \circ \sigma \theta i \hat{\kappa} \alpha \mathrm{l}$ ' detract from pathetic effects that sit well with this style--partly disagreeing with pseudoDemetrius (Eloc. 57, see above).

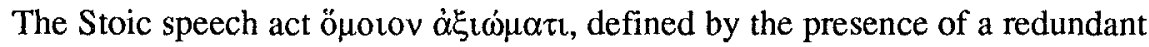
word or of $\pi \dot{\alpha} \theta \circ \zeta$ and illustrated by poetic examples (see above p. 236), hovers at the intersection of logic and the type of stylistic observations discussed here. The poetic examples indicate that constructions that are directly relevant to logic are being supplemented (in order to arrive at something like an exhaustive description) by material drawn from the common stock of the student of language and literature, namely poetry. An emphasis on the presence of redundancy vis-a-vis the regular axiom in this specific type is confirmed by Sextus Empiricus' description of the same type of sentence as $\pi \lambda \dot{o}$ ov $\pi \dot{\alpha} \xi\llcorner\omega \dot{\alpha} \mu \tau o \zeta(M .8 .73)$. In both cases, however, the formal observation is made subservient to a general focus on logic: the speech act is defined with direct reference to the $\dot{\alpha} \xi i \omega \mu \alpha$ pure and simple, the bearer of truth and falsity and the central speech-act type in Stoic logic. ${ }^{23}$ A prudent conclusion would be that the Stoics' wide interpretation of the scope of their dialectic led them to make observations on form and style over and above the requirements of logic, thus providing stimuli for later students of linguistic phenomena, who emphasized the stylistic side and downplayed that of logic.

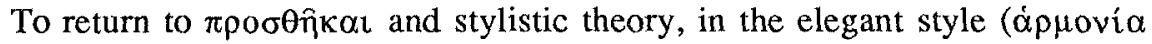
$\gamma \lambda \alpha \phi \cup \rho \alpha \dot{)}) \pi \rho \sigma_{0} \hat{i} \kappa \alpha \imath$ are useful and necessary to achieve the full intended stylistic effect. This style strives after $\dot{\eta} \delta o v \dot{\eta}$ and $\kappa \alpha \dot{\alpha} \lambda \lambda \varsigma_{\zeta}$ rather than rugged grandeur, and $\pi \rho \circ \sigma \theta \hat{n} \kappa \alpha \mathrm{l}$ that are not strictly speaking necessary for the sense contribute to that purpose. ${ }^{24}$ Again, $\pi \rho \circ \sigma \theta \eta \dot{\kappa} \eta$ may be replaced with its synonym $\pi \alpha \rho \alpha \pi \lambda \eta \dot{\eta} \rho \omega \alpha .{ }^{25}$ Secondly, a pleasant effect is contrived by euphony, ${ }^{26}$ and again $\pi \rho 0 \sigma \theta \hat{n} \kappa \alpha$ are a helpful tool. ${ }^{27}$ And thirdly, the $\dot{\alpha} \rho \mu$ ovi $\alpha \gamma \lambda \alpha \phi v \rho \alpha$ avoids hiatus by adding words that again are not strictly speaking necessary, but prevent roughness (D. H. Dem. 40.215.19ff.):

21 D. H. CV 22.98.1f.; cf. Dem. 39.213.6ff.

22 D. H. Dem. $38.210 .14 \mathrm{ff}$.

23 Albert Rijksbaron pointed out to me that in the sentence 'how like Priam's sons the cowherd is' the truth of the underlying axioma is presupposed-in that sense the sentence truly conveys 'morc than an axioma'. This is true and relcvant. However, it only goes for the examples with $\dot{\omega} \zeta$, not for those with $\gamma \varepsilon$.

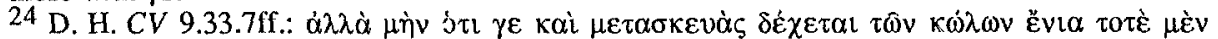

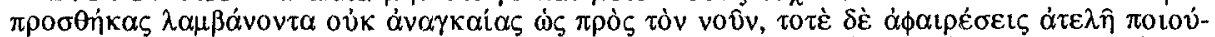

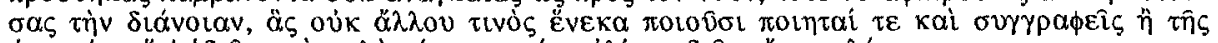

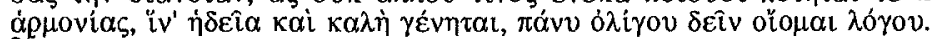

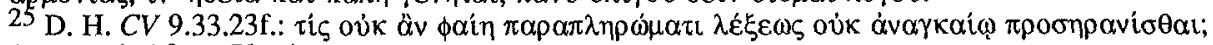
(sc. a period from Plato).

26 D. H. Dem. 40.214.23.

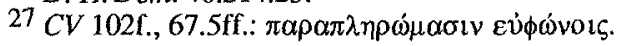




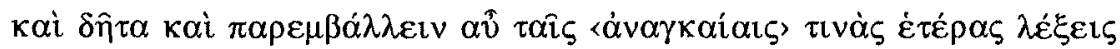

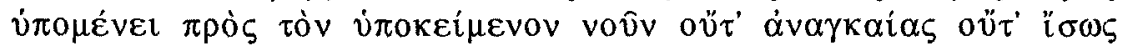

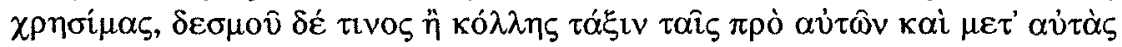

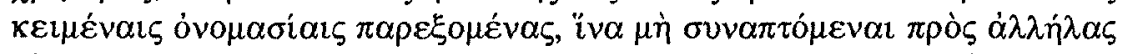

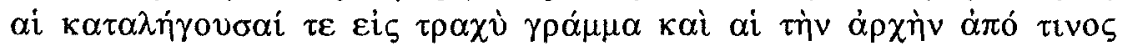

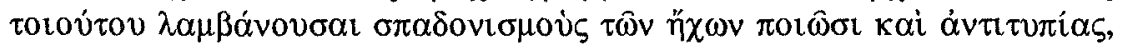

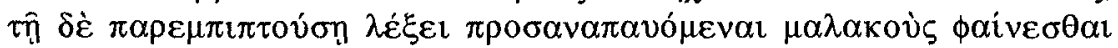

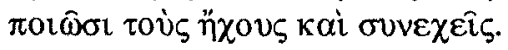

'Indeed, [the smooth style] is quite prepared to allow unnecessary words to be added to the necessary which contribute nothing to the underlying sense, and perhaps have no useful purpose, but are intended to serve as a sort of connection or bonding between what precedes and what follows, so that words ending and words beginning with rough letters may not clash, choking the sound and producing dissonance. The intervening phrase provides a rest and makes the sound appear soft and unbroken', tr. Usher

Dionysius proceeds to state that in this style the aim is 'to draw and weave together ( $\sigma v \sigma \pi \alpha \sigma \theta \hat{\eta} v \alpha \mathrm{l}, \sigma v v v \phi \alpha \dot{v} \theta \alpha \mathrm{l}$ ) all the members of the period, achieving the impression of one continuous sound-stream ( $\left.\mu \mathrm{L} \hat{\alpha} \zeta \lambda \hat{\varepsilon}^{\xi} \xi \varepsilon \omega \zeta\right)^{\prime}$ (ibid. 216.8ff.). ${ }^{28}$ The description sounds as a paraphrase of the concept of the $\sigma \dot{v} v \delta \varepsilon \sigma \mu \rho \zeta \pi \alpha \rho \alpha \pi \lambda \eta \rho \omega$ $\mu \alpha \tau \kappa o ́ \zeta: \pi \alpha \rho \varepsilon \mu \beta \alpha \dot{\alpha} \lambda \lambda \varepsilon \iota v$ and $\pi \alpha \rho \varepsilon \mu \pi t \pi \tau o v$ on; the fact that they do not make a necessary contribution to the meaning; and the function of the intercalated words as $\delta \varepsilon \sigma \mu o ́ s$ and kó $\lambda \lambda \alpha$. The description of how roughness is avoided is also reminiscent of Trypho's view of these words as 'padding'. ${ }^{29}$ However, there is no compelling evidence that Dionysius has the restricted group of the $\pi \alpha \rho \alpha \pi \lambda \eta \rho \omega \mu \alpha \tau t$ Koi in mind, and rather a lot of circumstantial evidence to suggest that he does not. ${ }^{30}$

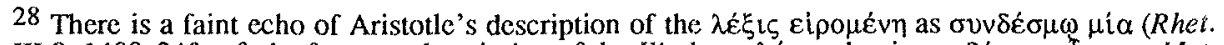

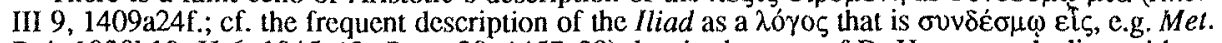
B 4, 1030b10; H 6, 1045a13; Poet. 20, 1457a29), but in the case of D. H. we are dealing with an effect of sound rather than structure, and as such it is incorporated in a description of the periodic, not the concatenated, style.

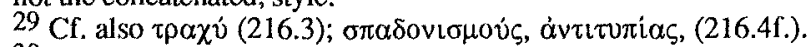

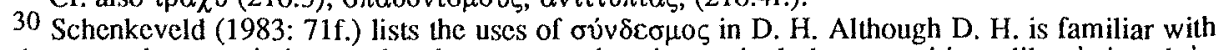
the term, he uses it in a rather loose way; thus it can include prepositions like $\dot{\varepsilon} \pi \dot{i}$ and $\dot{\varepsilon} v$ (Schenkeveld 1983: 74). Sclienkeveld does not discuss D.H.'s use of sub-groups of 'conjunctions',

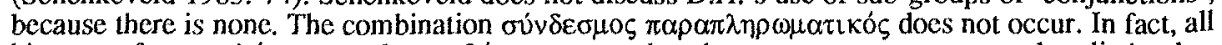
his uses of $\pi \alpha \rho \alpha \pi \lambda \dot{\eta} \rho \omega \mu \alpha$ and $\pi \rho 0 \sigma \theta \dot{k} \mathrm{k} \eta$ suggest that they express a more general stylistic phenomenon, and are not connected with a specific type of 'conjunction' as a technical term. The more

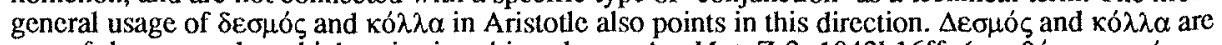

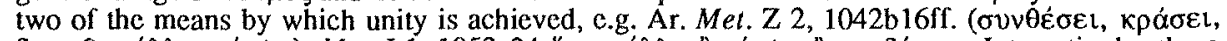

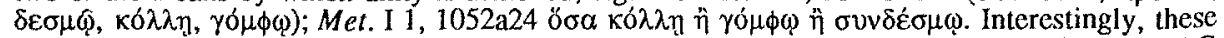
metaphors are picked up and applicd to all the lesser parts of speech by Ammonius In Ar. Int., CAG IV 5.12.25ff.:

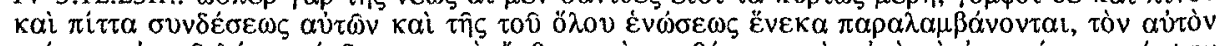

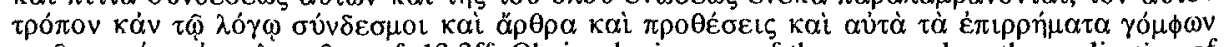

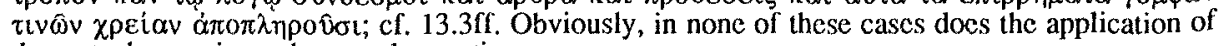
the metaphor envisage the parapleromatics. 
Undue application of these stylistic devices to produce a fully periodic style at all cost and irrespective of whether the subject-matter lends itself to it can lead to criticism, which Isocrates in particular comes in for (D. H. Isoc. 3.58.18ff.):

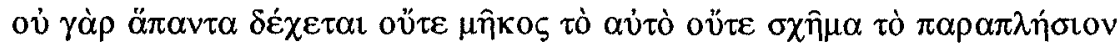

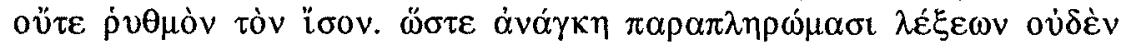

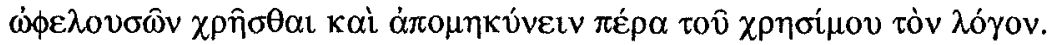

'For not everything lends itself to the same length or a similar form or the same rhythm. And so it becomes necessary to use fillers of words that do not have any use, and to draw out the speech over and above what is useful'

Now, if we compare the texts adduced so far, it becomes clear that the $\pi \alpha \rho \alpha \pi \lambda \eta \rho \omega-$ $\mu \alpha \tau$ кoi $\sigma u ́ v \delta \varepsilon \sigma \mu o t$ were associated particularly closely with a stylistic function that could also be fulfilled by other parts of speech or even whole phrases: if applied well, if fills out the sentence, not by the necessary completion of the thought, but by making it smoother, remedying hiatus, and providing supple transitions. Thus, it is the

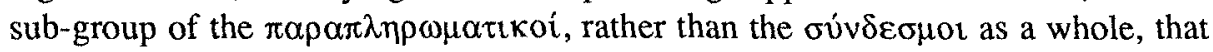
becomes the focus for remarks on absence of meaning.

Our texts make it equally clear that the delimitation of the group must have been vague originally, when $\pi \alpha \rho \alpha \pi \lambda \eta ি p \omega \mu \alpha$ was a general stylistic qualification for a word (group) that was strictly speaking redundant. ${ }^{31}$ Of the 'literary critics', only pseudo-

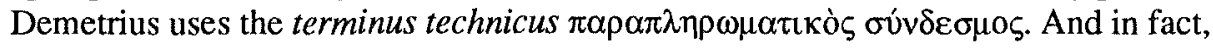
corrupt transmission of pseudo-Demetrius was promptly assumed to get rid of the example $\pi \rho$ ó $\varepsilon \rho o v$. But again, a comparison with the other stylistic criticisms seems to suggest differently: when Longinus points out that it is hard to convey $\pi \alpha \dot{\theta} \theta$ ک

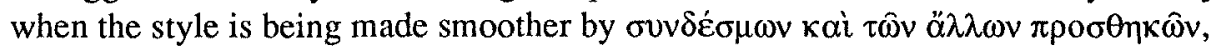
the sentence he quotes as an example contains words like $\alpha \alpha i \mu \eta \dot{v}$, and $\gamma \varepsilon \mu \eta \dot{v} v$, but also $\pi \rho \hat{\omega} \tau o v \mu \varepsilon \dot{v}, \varepsilon i \tau \alpha \delta \dot{\varepsilon}$, and another $\varepsilon i \tau \alpha$ (21.1). In Lucian's harangue against Atticism, Lexiphanes, the main character is given an emetic to get rid of his redundant Atticistic phrases, which include $\mu \hat{\omega} v, \kappa \hat{\alpha} \tau \alpha, \delta \dot{\eta} \pi \circ v \theta \varepsilon v$ and $\alpha{ }^{\top} \tau \tau \alpha .{ }^{32}$ While later theory does not call these words $\sigma v 0 \delta \varepsilon \sigma \mu \circ t \pi \alpha \rho \alpha \pi \lambda \eta \rho \omega \mu \alpha \tau$ coi, it will point out that

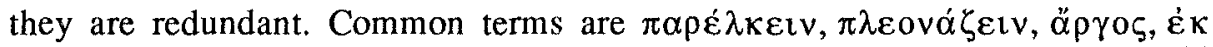

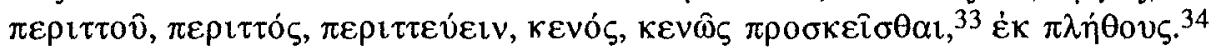

31 In Sch. D. Th. 461.15ff. $\pi \alpha \rho \alpha \pi \lambda \eta \dot{n} \rho \omega \alpha$ is one in a series of stylistic/rhetorical phenomena, and it

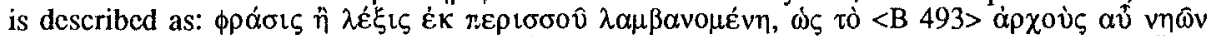

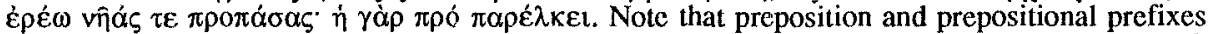

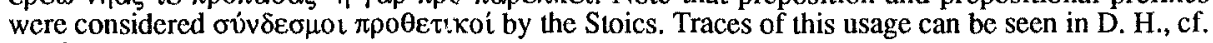
previous note.

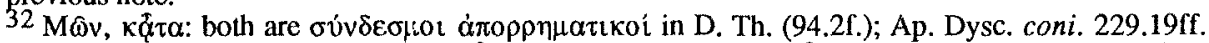

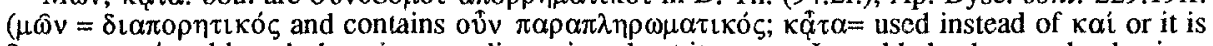
$\delta 1 \alpha \pi 0 p \eta \tau \leftarrow \kappa o ́ \zeta$, although there is some discussion about its status. It could also be an adverb, since it contains elta (so Trypho)).

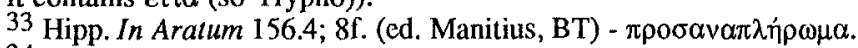

34 Cf. Ruijgh (1971: § 60); Ruijgh points out that $\pi \alpha \rho \alpha \pi \lambda \eta \rho \omega \mu \alpha \tau \iota k o ́ \varsigma$ is not synonymous with these terms, which always denote redundancy in a certain context, i.c. as an accidental feature, while

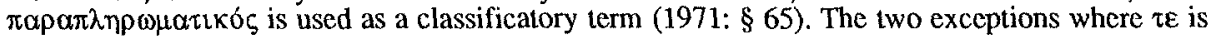


Elink Sterk has collected all the words whose redundant use has been noted by ancient Greek scholiasts, glossographers and Atticists (II 41ff.). Among the exam-

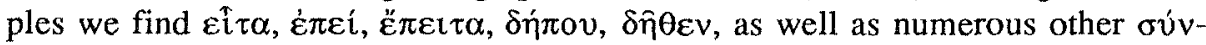
$\delta \varepsilon \sigma \mu o t$ and adverbs, but also a word like ö $\tau \tau \alpha$, singled out by Lucian. ${ }^{35}$ Again, while there may often be critical overtones in designating the use of a word 'redundant', the terms as such do not exclude the possibility that their effect is to beautify the language. ${ }^{36}$

Thus, there is a long-standing stylistic awareness of the incidental ornamental, meaningless use of words that do signify in other contexts. If their ornamental effect is doubted, such a use constitutes a stylistic faux-pas. The part of speech in which this phenomenon was observed to occur most frequently was the conjunction. Even after it had been established that conjunctions in general are not meaningless (like Aristotle had contended), but express the relationships-which have a reality of their own-between states of affairs (Stoa), ${ }^{37}$ the discussion about meaningless words still naturally gravitated towards this part of speech, but it concentrated on a sub-group, the $\pi \alpha \rho \alpha \pi \lambda \eta \rho \omega \mu \alpha \tau \kappa o$. A pollonius Dyscolus still feels the necessity of vigorously combating a majority view that these words have no meaning at all ${ }^{38}$ Supporters of that idea may have felt backed up by the very name of the sub-group, but Apollonius explains the name as a simple matter of classificatory convenience. There is no point in endlessly increasing the number of subcategories, each covering a sub-set of possibly one word only. The system of grammar should be kept simple, elegant and easy to memorize. These words have meaning, but they are rarely used for that. Usually, their euphonic function explains their appearance, without their making any contribution to the meaning; even so they are useful, and this is the use they are named for..$^{39}$ Apollonius' parallel for this terminological solution of convenience is the word

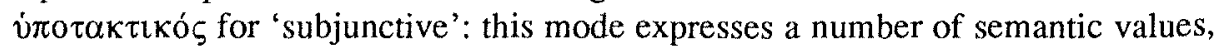

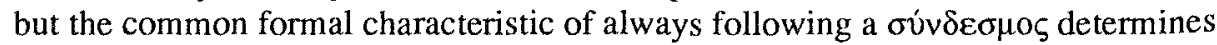
the name. ${ }^{40}$

called $\pi \alpha \rho \alpha \pi \lambda \eta \rho \omega \mu \alpha \tau \kappa o ́ \varsigma$, are Ap. Dysc. $a d v .148 .5$; Sch. Hom. O 124 (Ruijgh 1971: $\S 68 \mathrm{f}$.). Note that Elink Sterk is confused about the use of $\dot{\varepsilon} \kappa \lambda \eta \eta_{000} \zeta$, which does not mean that the word used is redundant, but that it is spelled in scriptio plena, i.c. without apocope (e.g. II $48 \gamma \varepsilon$, not $\gamma^{\prime} ; 66$ $\tau \varepsilon$, not $\left.\tau^{\prime}\right)$.

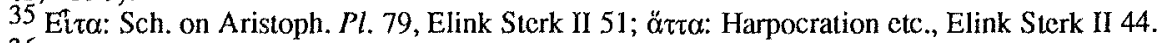

${ }^{36}$ Cf. e.g. the use of $\pi \varepsilon \rho \iota \tau \tau$ ć $\zeta$ signaled above (p. 240), in D. H. Dem. 24.182.20f.; cf. D. H. CV

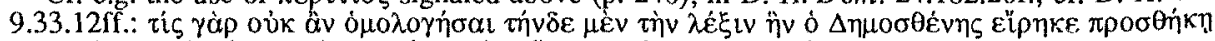

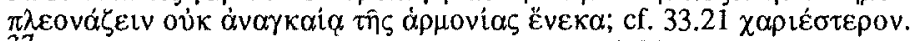

37 Frede (1977: 74), (1978: 62ff., 65f.), Atherton (1993: 302ff.).

38 Ap. Dysc. coni. 247.22 fr.

${ }^{39}$ Coni. 252.29ff. It should be pointed out that Elink Sterk's otherwise useful contribution is fundamentally vitiated by his view that a word without meaning cannot have anything to contribute to the beauty of a text (better: Jahn 1847: 37ff.; Kroon 1995: $37 \mathrm{n}$. 6). Therefore, he refuses to allow that the $\pi \alpha \rho \alpha \pi \lambda \eta \rho \omega \mu \alpha \tau \iota \kappa o i, ~ c v e n ~ i f ~ j u s t ~ u s e d ~ q u a ~ \pi \alpha \rho \alpha \pi \lambda \eta \rho \omega \mu \alpha \tau \iota$ koi (i.c. precisely in the cases where the name is not a misnomer), can be meaningless.

40 Ap. Dysc. synt. 377.8ff.; D. H. also knows this principle in naming the elements and the three

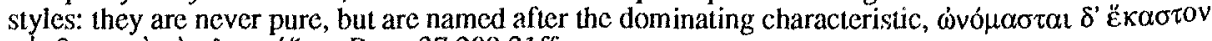

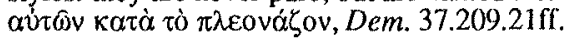


I began this article by pointing out that the ancient meristic system allowed room for residual cases: the class of adverbs formed a natural receptacle for them, and within the class of the syndesmoi, so did the parapleromatic ones. All syndesmoi which would otherwise have formed a semantic class of their own fitted into this category. In this way it contributed to the economy of the system. The reason why paraplero-

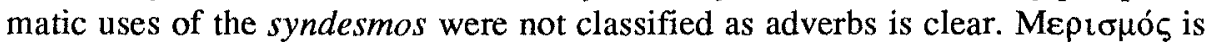
primarily decided on the ground of meaning. ${ }^{11}$ If a word incidentally behaves as if it belonged to a different word class, that instance will be classified accordingly. But parapleromatic uses of the syndesmos do not have any distinguishable meaning at all, and therefore retain their classification, as would happen with any other pleonastically used part of speech. The difference is that with other words pleonastic use is the exception, while here it is the rule, to the point where the whole sub-group is named for this use. Chaeremon allows the formal behaviour of these words (i.e. the fact that they are homonyms of regularly signifying 'conjunctions') to be the determining factor in their $\mu \varepsilon \rho t \sigma \mu$ s $_{\text {. }}{ }^{42}$ Apollonius strengthens this argument by putting their redundant use on a par with that of any other part of speech, and pointing out that incidental redundancy is never a reason to assign a word to a different part of speech (coni. 249.22ff.). He then proves that every $\sigma u ́ v \delta \varepsilon \sigma \mu o \zeta \pi \alpha \rho \alpha \pi \lambda \eta\rceil \omega \mu \alpha \tau t \kappa o ́ s$ is also used in a meaningful way (coni. 249.31ff.), thus putting this sub-group firmly in the realm of the normal and regular.

In this contribution I looked at the grammatical class of the $\sigma 0 v \delta \varepsilon \sigma \mu o t \pi \alpha p \alpha-$ $\pi \lambda \eta \rho \omega \mu \alpha \tau$ кó $㇒$ from a specific angle. Two factors contributed to its development. One is that discussions about whether or not conjunctions have meaning were replaced with or focused on the question of whether or not this specific residual group had any. Here I emphasized the economy of the grammatical system, which has its own requirements that can take precedence over linguistic realities. The other factor is the discussion about the stylistic impact of conjunctions. Here, too, we observed a shift from early rhetorical admonitions about the most effective use of corresponding syndesmoi to an interest in an issue that directly affected the distinction of the parapleromatics: the rhetorical and stylistic interest in redundancy and its effects. This was an old issue, but here too, the focus had to be narrowed. Virtually any word or even phrase could be used redundantly, but it seemed especially relevant in the case of the syndesmoi, if no longer for the whole group, then certainly for this sub-set that even got to derive its name from it.

Not only particles, but also articles can be parapleromatic. They are not neces-

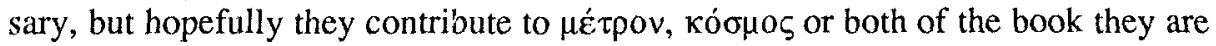
helping to fill. Certainly there can be no $\alpha$ k $\alpha$ lpi $\alpha$ in their expressing their admiration for the author of the Odyssey around epic $\tau \varepsilon$.

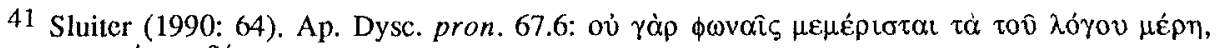

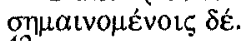

42 Apud Ap. Dysc. coni. 248.11f. 


\section{Bibliography}

Atherton, C.

1993 The Stoics on Ambiguity. Cambridge

Baratin, $M$.

1989 La naissance de la syntaxe à Rome. Paris

Belli, G.

1982 'Aristotele e Posidonio sul significato del "syndesmos"'. Aevum 61, 105-7 Elink Sterk, J.W.

1845-46 'Grammatica Zetemata -- De Parapleromaticis'. Symbolae Literariae 7, 3-63 [=I]; 8, 3-71 [= II]

Frede, $\mathrm{M}$.

1977 'The Origins of Traditional Grammar'. In: R.E. Butts and J. Hintikka (eds), Historical and Philosophical Dimensions of Logic, Methodology and Philosophy of Science. Dordrecht, pp. 51-79

1978 'Principles of Stoic Grammar'. In: J.M. Rist (ed.), The Stoics. BerkeleyHellwig, A. Los Angeles-London, pp. 27-75

1974 'Zur Funktion und Bedeutung der griechischen Partikeln'. Glotta 52, 145 71

Jahn, C.F.

1847 Grammaticorum graecorum de coniunctionibus doctrina. Greifswald Kroon, C.M.

1995 Discourse Particles in Latin. A Study of nam, enim, autem, vero and at. Amsterdam

Ruijgh, C.J.,

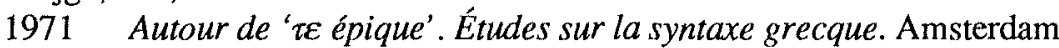

Schenkeveld, D.M.

1983 'Linguistic Theories in the Rhetorical Works of Dionysius of Halicarnassus'. Glotta 61, 67-94.

1984 'Studies in the History of Ancient Linguistics II. Stoic and Peripatetic Kinds of Speech Act and the Distinction of Grammatical Moods'. Mnemosyne 37, 291-353

1988 'From Particula to Particle - the Genesis of a Class of Words'. In: I. Rosier (éd.), L'héritage des grammairiens latins de l'antiquité aux lumières. Actes du Colloque de Chantilly, 2-4 septembre 1987. Paris, pp. 81-93

Sluiter, I.

1990 Ancient Grammar in Context. Contributions to the Study of Ancient Linguistic Thought. Amsterdam

Tosi, R.

1988 Studi sulla tradizione indiretta dei classici greci. Bologna 